\title{
Katrin Rudolphi: Nord-Amerika in Raynal: zur Konstruktion eines Diskurses
}

\section{Rita Unfer Lukoschik}

\section{Q OpenEdition}

1 Journals

\section{Edizione digitale}

URL: https://journals.openedition.org/studifrancesi/40797

DOI: 10.4000/studifrancesi.40797

ISSN: 2421-5856

\section{Editore}

Rosenberg \& Sellier

\section{Edizione cartacea}

Data di pubblicazione: 1 juillet 2004

Paginazione: 199-200

ISSN: 0039-2944

\section{Notizia bibliografica digitale}

Rita Unfer Lukoschik, «Katrin Rudolphi: Nord-Amerika in Raynal: zur Konstruktion eines Diskurses», Studi Francesi [Online], 142 (XLVIII | I) | 2004, online dal 30 novembre 2015, consultato il 09 septembre 2021. URL: http://journals.openedition.org/studifrancesi/40797 ; DOI: https://doi.org/10.4000/studifrancesi. 40797

Questo documento è stato generato automaticamente il 9 septembre 2021.

\section{(c) (1)}

Studi Francesi è distribuita con Licenza Creative Commons Attribuzione - Non commerciale - Non opere derivate 4.0 Internazionale. 


\title{
Katrin Rudolphi: Nord-Amerika in Raynal: zur Konstruktion eines Diskurses
}

\author{
Rita Unfer Lukoschik
}

\section{NOTIZIA}

KATRIN RUDOLPHI: Nord-Amerika in Raynal: zur Konstruktion eines Diskurses, Frankfurt am Main, Peter Lang, 2002 («Studien und Dokumente zur Geschichte der Romanischen Literaturen», 40), pp. 180.

$1 \quad$ L'Histoire philosophique et politique des établissements et du commerce des Européens dans les deux Indes di Guillaume-Thomas Raynal esce in edizione clandestina nel 1770 e prende a circolare ufficialmente a partire dall'edizione parigina del 1772. Il suo successo in tutta Europa è immediato ed enorme: moltissime, secondo gli ultimi studi ben 152, sono le edizioni che l'opera ha in francese nel giro di pochi anni, tra il 1772 ed il 1794, cui già all'epoca si accompagnano pubblicazioni di précis, observations, estratti 'ragionati', ed altrettanto frequenti traduzioni, anche in italiano, che all'originale seguono a ruota, facendo di Raynal e del suo libro oggetto di accesa discussione nell'Europa colta del tempo.

2 Presto tuttavia, già immediatamente a seguito della Rivoluzione francese, autore ed opera cadono in dimenticanza e fino agli anni ottanta del $\mathrm{XX}^{\circ}$ secolo si contano sulle punta delle dita gli studi che se ne occupano. Soprattutto per merito di Hans-Jürgen Lüsebrink dell'università di Saarbrücken, che nel giro di pochi anni dedica una buona decina di studi, singoli saggi e volumi miscellanei, in tedesco e francese all'abate Raynal ed al suo libro, si registra a partire dal 1981 un fiorire in crescita esponenziale di testi dedicati all'Histoire su cui viene per ora a fare il punto la tesi di dottorato che Katrin Rudolphi ha presentato nel 2001 alla Technische Universität di Berlino. 
3 La volenterosa autrice propone un non disutile vademecum attraverso la vasta produzione di studi recentemente apparsi non solo in area di lingua tedesca sul tema del suo lavoro, offrendo come originale contributo l'analisi della costruzione del discours in senso foucaultiano che Raynal genera con il suo testo sul tema dell'esotismo letterario relativamente all'America del Nord e di cui vengono ripercorsi stilemi, immagini e concetti filosofici, segnatamente riferentesi al concetto di verità usato dall'abate.

4 Va da sé che anche nell'analisi di Rudolphi è fortemente presente la lettura delle tesi di Edward Said, di cui si rintraccia ormai quasi obbligatoriamente la presenza nei recenti studi sull'alterità culturale in area di lingua tedesca, come si è esposto nella recensione al libro di Karl Hölz: Zigeuner, Wilde und Exoten. Non si avranno dunque grosse sorprese nell'accompagnare la studiosa sulle tracce dell'esotismo 'ideologico' di Raynal, alla ricerca di strategie di egemonia culturale che si iscrivono nelle pieghe del testo.

5 Meritori restano tuttavia sia l'attenta presentazione del materiale nordamericano all'interno dell'Histoire, con particolare riguardo al mito del buon selvaggio, sia la precisa contestualizzazione del discours di Raynal all'interno della sua epoca, in rapporto alle sue fonti, nella 'ricezione dialogica' del testo che si rispecchia in autori come Mandrillon, Chastellux e Genty, nella frizione ricettiva che ne scaturisce in scrittori piu tardi che, come Chateaubriand, lessero intensamente l'Histoire per approdare poi ad altri lidi dello stesso continente.

6 Con il suo Nord-Amerika in Raynal: costruzione di un discours Katrin Rudolphi offre in summa un'agile pubblicazione che, chi si occupa di Raynal e di esotismo americano, dovrà senz'altro tener presente, anche se, hélas, la consultazione ne viene ingiustamente penalizzata dall'assoluta mancanza di indici. 